\title{
A representação do silêncio no cinema sonoro
}

The representation of silent in sound movies

La representación del silencio en el cine sonoro

\begin{abstract}
Yasmin Pires ${ }^{1}$ (D) 9
André Villa ${ }^{2}$

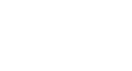

${ }^{1}$ Universidade Federal do Pará, Belém, Pará, Brasil, yasminpiresf@gmail.com

${ }^{2}$ Universidade Federal do Pará, Belém, Pará, Brasil, avandrevilla@gmail.com
\end{abstract}

\section{Resumo}

Mediante a noção de silêncio suscitada pelo pensamento de John Cage, este artigo objetiva investigar de que forma os filmes sonoros, por meio de recursos imagéticos e acústicos, representam o silêncio. Para tanto, o trabalho busca entender previamente de que forma o silêncio se constrói em nossa cultura e percepção, para em seguida adentrar na análise de filmes que possam revelar as articulações da estética cinematográfica envolvidas em projeções que estimulam a sensação de silêncio.

Palavras-chave: Cinema sonoro. Representação. Silêncio.

\begin{abstract}
Through the John Cage's comprehension of silence, this article aims to study how sound movies represents silence by imagery and acoustic resources. Therefore, the work first establishes the understanding of the cultural construction of our perception of silence, and then analyze selected movies that can reveal which articulations of cinematic aesthetics are involved in projections that stimulate sensation of silence.
\end{abstract} Keywords: Sound movies. Representation. Silence.

\section{Resumen}

Mediante la comprensión de silencio suscitada por el pensamiento de John Cage, este artículo objetiva investigar de qué forma las películas sonoras, por medio de recursos imagéticos y acústicos, representan el silencio. Así, el trabajo busca entender previamente de qué forma el silencio se construye en nuestra 
cultura y percepción, para después adentrarse en el análisis de películas que puedan revelar las articulaciones de la estética cinematográfica incluidas en proyecciones que estimulan la sensación de silencio.

Palabras clave: Cine sonoro. Representación. Silencio.

\section{Introdução}

Silêncio, também, é um efeito acústico, mas somente onde sons podem ser ouvidos. A apresentação do silêncio é um dos efeitos dramáticos mais específicos do filme sonoro. Nenhuma outra [arte] pode reproduzir o silêncio, nem pintura ou escultura, nem literatura ou o filme silencioso poderia. (BALAZS, 1985, p. 117, tradução nossa).

Inserido em uma contemporaneidade que frequentemente nos cerca de ruídos e informações excessivas, o silêncio emerge no cinema atual como um recurso artístico peculiar. Enquanto elemento da linguagem cinematográfica, o seu potencial dramático pode ser explorado de formas variadas na narrativa, bem como pode se manifestar de diferentes maneiras na abordagem fílmica.

A noção de "silêncio" concentra diversas conotações. As significações mais recorrentes e difundidas do termo evocam uma mera qualidade oposta ao som, uma simples suspensão de ruídos ou de uma ausência de fenômenos acústicos. Noções como vazio, obscuridade e inação são frequentemente atribuídas de forma simbólica ao termo em consequência de alguns aspectos intrínsecos à cultura ocidental. Visando a uma desconstrução dessa ideia, este artigo trabalha em uma perspectiva na qual a ausência absoluta de som é considerada uma situação altamente improvável, configurando, desse modo, o silêncio como algo diverso do sentido mais recorrente. Este texto desenvolve uma abordagem que considera sua apreensão como a construção de um atributo perceptivo resultante de uma intenção ligada à ação da percepção auditiva

O pensamento que subsidia a base dessa explanação tem suas origens em John Cage (1961) que, como veremos adiante, afirma a impossibilidade de execução do silêncio. Na rigidez de sua apreensão física, o silêncio só seria exequível no vácuo. Dessa forma, se não podemos apenas eliminar os sons, questiona-se: como se faz a representação 
do silêncio nas diferentes artes e, principalmente, no cinema? Em termos cinematográficos, ele pode ser representado tanto por meios acústicos quanto por artifícios visuais, se revelando como um rico recurso semântico e artístico. A manipulação de cortes, cores, gestos, sons, movimentos, enquadramentos e luz é utilizada pelos cineastas para evocar sensações silenciosas no espectador, suscitando então experiências multissensoriais, visto que são provocadas por outros sentidos (além da audição).

Isso posto, esta pesquisa pretende colocar algumas reflexões que envolvem a linguagem articulada em torno da representação do silêncio no cinema sonoro. Sobre a escolha por filmes sonoros, é necessário esclarecer que essa categoria, que se inaugura com a inserção da trilha sonora no final dos anos 1920 e principalmente com o referencial do filme O Cantor de Jazz (The Jazz Singer, Alan Crosland, 1927), é uma categoria que diz respeito ao que Fred Camper (1985) chama de "verdadeiros filmes silenciosos". Neles, o silêncio fílmico trata-se de uma eleição artística inserida no filme deliberadamente, uma opção estética, e não de uma característica imposta por uma limitação técnica e/ou tecnológica, tal qual nos filmes "mudos" - ou silenciosos - ou mesmo nos filmes "mudos" munidos de acompanhamento sonoro.

A partir disso, para desenvolver essa pesquisa, esse texto começa com um delineamento histórico que enfatiza a construção cultural do silêncio, explicitando a interpretação inovadora de John Cage. Por fim, serão analisados filmes que expõem as principais formas de representação do silêncio no cinema sonoro, apresentando assim uma proposta que foca nas possibilidades de experiências multissensoriais.

\section{A construção cultural do silêncio}

O silêncio, quando definido como uma qualidade acústica, pode ser facilmente identificado pelos nossos ouvidos. Todavia, delinear um conceito preciso do que seja o silêncio não é uma tarefa fácil, pois esse termo não necessariamente trata da simples ausência de som ou da suspensão de todo e qualquer ruído, conforme foi rapidamente exposto acima. Um aprofundamento teórico no tema nos faz perceber que as noções de silêncio, ruído e som estão ligados a aspectos culturais que se desenvolveram ao longo do tempo, e que se entrelaçam intimamente entre si. Dessa forma, focando no princípio da construção cultural da escuta humana, destacaremos as principais qualidades simbólicas e conceituais que lhe foram atribuídas em seu percurso de desenvolvimento histórico, e qual dessas perspectivas melhor o contempla em sua utilização no cinema. 
De início, podemos registrar a importância de seu atributo divino no ocidente, o qual se manteve em vigor até aproximadamente o século XIII - época dos últimos grandes místicos cristãos. Sinônimo de quietude, o silêncio poderia ser encontrado em contato com a natureza, nos santuários ou igrejas, locais que estariam preservados dos sons e dos ruídos. Esses seriam espaços onde as pessoas se refugiariam e se relacionariam com dimensões superiores da vida, posto que, nesse contexto, o silêncio seria capaz de promover a possibilidade de uma elevação mental em uma aproximação do divino. Depois disso, como efeito das sucessivas mudanças na dinâmica econômica das sociedades, o gesto de contemplação começou a desaparecer de forma gradativa na cultura ocidental (SCHAFER, 2011, p. 357).

No século XVII, Galileu Galilei sugere a infinitude do universo. Mediante essa ideia, o filósofo Blaise Pascal considerou temeroso: "o silêncio eterno desses espaços infinitos me assusta" (SCHAFER, 2011, p. 357). Essa postura revela, em síntese, o aspecto negativo que o silêncio adquiriu e que tende a se perpetuar até os dias atuais (exceto pelas quebras suscitadas por pensamentos artísticos e filosóficos que serão posteriormente expostos). No sentido apreendido por Pascal, o silêncio representa a ausência de atividade humana, logo, a ausência de vida em uma perspectiva antropocêntrica. Isso pode ser derivado do olhar adotado por diversas religiões, em que muito é falado acerca de um silêncio primordial, o qual antecede a criação divina do ser humano. Ao silêncio, nesse caso, é inerente à noção de desconhecido, de obscuridade, bem como a ideia de que a morte (a não existência) é silenciosa, e a vida é ruidosa. Se o homem teme a morte, ele evita o silêncio a fim de nutrir a sua fantasia de vida eterna. Onde quer que esteja ele se cerca de ruídos para sentir-se seguro, receoso da solidão e do vazio. Daí derivam concepções como a de Jacques Attali, autor que, em um trabalho sobre a noção de ruído, constata: "nada se passa de essencial onde o ruído não esteja presente" (ATTALI, 1977, p. 7).

Já na modernidade, o silêncio passa novamente por processos históricos de ressignificação, como podemos constatar nas obras dos futuristas italianos, dos quais fazia parte Luigi Russolo (músico e compositor futurista). Russolo compunha obras para os intonarumori, "instrumentos ruidosos", construídos sob a inspiração e a necessidade de reproduzir os ruídos da vida moderna - tudo o que existia antes da ascensão das máquinas e seus ruídos era silêncio. Ou seja, caracterizava-se pela ausência dos sons industriais inerentes ao cenário modernoํ. Mas é necessário entender que, 
para os futuristas, o ruído não se caracterizava como um som indesejável, algo que nos incomoda ou nos atrapalha na vida cotidiana. Russolo relaciona a transformação do mundo moderno e a nossa apreensão dessa nova paisagem sonora que nos cerca ${ }^{2}$. Para além da exaltação de uma nova era, o compositor futurista faz referência ao fato que, com a inserção das máquinas em nosso cotidiano, nós nos habituamos a um novo limiar de tolerância de ruídos, reconfigurando assim a nossa ideia de silêncio para o que precedeu o desenvolvimento industrial e a atual configuração das cidades, cheias de motores, alto-falantes, buzinas e sons afins. Mas principalmente, nesse manifesto Russolo faz referência a um questionamento estético musical visto que, para ele, é necessária uma diversificação do que nós definimos como "som musical", abrangendo nessa gama não somente os sons de instrumentos musicais e as vozes, como também esses ruídos da modernidade, do futuro. Esse propósito ressurgiria e seria renovado por artistas, músicos e pesquisadores em diversas ocasiões durante todo o século XX (e.g., Halim El-Dabh, Pierre Schaeffer, Robert Beyer e Herbert Eimert, Luening e Ussachevsky, John Cage), e seria, por fim, completamente dissipado na proposta da obra Déserts (1950-1954) de Edgard Varèse para instrumentos de sopro, percussões e fita magnética, obra que, segundo Cage, "entra no domínio do som em si, sem o separar em dois", sem diferenciar som musical e ruído. Após esses desenvolvimentos oriundos da dita música contemporânea e em total ruptura com os pensamentos dos séculos precedentes, o que passa a definir a qualidade musical de um som não está mais ligado às normas estéticas baseadas em regras científicas como parâmetro de julgamento estético (e.g., acústica musical). Doravante, é o contexto musical que o compositor propõe, em face de expectadores com seus modos de escuta já amplamente transformados, que dota as estruturas sonoras de uma conotação musical, sejam elas instrumentais, ruidosas ou mesmo silenciosas.

Assim como a noção de ruído, a compreensão do silêncio nos estudos musicais ocidentais se transformou durante os tempos. É provavelmente com Franco de Colônia e sua obra Ars cantus mensurabilis, no século XIII, que se instala uma noção de tempo métrico tanto na duração dos sons como na duração da pausa ou silêncio. $\mathrm{O}$ silêncio passa assim de uma simples interrupção imprecisa entre as sequências vocais (articulações respiratórias nos fraseados) a uma função musical realmente estética. No entanto, ainda que o silêncio tenha assumido diversas funções, principalmente no período da música ocidental tonal escrita, ele foi majoritariamente considerado como 
um recurso para colocar em valor os sons que o precedem ou os que o seguem, um lapso temporal entre dois sons ou grupos de sons, a interrupção na comunicação de um som, uma "pausa" na produção de notas ou sons musicais. Por vezes, o silêncio é pensado como uma tela branca, um fundo virgem onde a figura do som emerge - em uma relação análoga à figura/fundo da abordagem proposta pela Gestaltteorie - ou mesmo como o abrigo do evento musical, uma bolha silenciosa que deve "protegê-lo" contra o ruído que, nesse contexto, se identifica enquanto som indesejado. Nota-se que na música existe uma consciência acerca da existência do silêncio evidenciada por essa busca pelo desenvolvimento de sua definição. Entretanto, aos nossos olhos e ouvidos contemporâneos, essas definições supracitadas ainda parecem demasiadamente restritas, pois tratam o silêncio como uma questão simples e dicotômica, designando-o como ausência de som, ausência de estímulos, uma simples sinalização para a mente que percebe uma forma de "pausa de pensamento entre dois instantes musicais", como nos diria Marie-Christine Forget (FORGET, 1995, nota 68).

Em contraste, no oriente, em função do estabelecimento de diferentes práticas da escuta, a construção do silêncio transcende essa visão dualista que o opõe ao som ou ao ruído. A solidificação de filosofias vinculadas ao taoísmo, por exemplo, faz com que o silêncio possa emergir como um estado positivo de plenitude de espírito e felicidade. Lao-Tsé, filósofo taoísta, incentiva o abandono da pressa das atividades cotidianas para que, por meio do silêncio, compreendamos o espírito do Tao - caminho (SCHAFER, 2011, p. 358). O silêncio, do ponto de vista oriental, não constitui, portanto, a ausência do verbo ou passividade. Caracteriza-se por uma experiência, um ato de introspecção que é uma busca. Isso se deve igualmente ao fato de que a cultura oriental desenvolve uma outra relação com o conceito de "nada", em comparação ao pensamento ocidental dominante. "Nada", bem como "silêncio", não proclamam o "vazio", tampouco negam uma existência ou unidade. Tais conceitos apenas se referem a algo cuja substância não está circunscrita, designando entes efêmeros, fluidos. Por conseguinte, o ser/existir para eles não se encontra centralizado na matéria ou no corpo, como o antropocentrismo faz crer. Assim, entende-se que não há finalidade, há um processo, um caminho e a constante formação (HELLER, 2011, p. 41-43).

À parte disso, até a década de 1940, a percepção do silêncio como "presença da ausência" de som, tal como vimos nos exemplos mencionados, encontrava-se fortemente cristalizada no ocidente. 


\section{Transformações contemporâneas na noção de silêncio}

Nos princípios da década de 1950, John Cage, compositor vanguardista e teórico musical norte-americano, insere novos métodos de criação e ação no âmbito artístico e reestrutura paradigmas acerca do silêncio. Em uma experiência vivida em uma câmara anecoica da Universidade de Harvard, Cage constatou que o silêncio, enquanto ausência, não existe. Frente a sua expectativa de fruir a plena ausência do som, deparou-se com a escuta de uma frequência aguda e outra grave, ao que o engenheiro que o acompanhava disse serem advindas do seu sistema nervoso em operação e o seu sangue em circulação, respectivamente. Em outras palavras, essas frequências eram sons produzidos pelo seu próprio organismo em funcionamento e que o acompanhariam até sua morte. Essa experiência o fez entender que os sons são gerados de maneira ininterrupta pelo acaso (CAGE, 1961, p. 8). A verificação da impossibilidade de execução do silêncio em seu sentido tradicional faz com que seu conceito se desloque para o senso de conjunto de ruídos não organizados (BOSSEUR, 1993, p. 37).

Inclinado às filosofias orientais, Cage deu continuidade a esse pensamento em sua obra e em sua produção intelectual, na qual ele relata outra experiência que foi determinante para suas reflexões e produções musicais baseadas sobre um pensamento sobre o silêncio. Durante uma apresentação informal de uma peça de seu amigo, o compositor Christian Wolff, Cage vivencia a seguinte situação:

Um dia, enquanto as janelas estavam abertas, Christian Wolff tocava uma de suas peças ao piano. Sons de tráfego e apitos de barcos eram ouvidos não somente durante os silêncios da música, mas, sendo sons fortes, eram mais facilmente ouvidos que os sons do piano. Ao final, alguém pediu a Christian Wolff para tocar a peça novamente, mas com as janelas fechadas. Christian Wolff disse que o faria com prazer, mas que isto não era realmente necessário visto que os sons ambientes não consistiam de maneira alguma em uma interrupção dos sons da música. (CAGE, 1967, p. 133, tradução nossa).

No ano de 1952, Cage cria a peça musical 4'33" para qualquer instrumentista ou formação instrumental. Ela foi executada pela primeira vez no Marverick Hall, em Woodstock, e apresentada pelo pianista David Tudor. A apresentação consistiu em um pianista que se colocou em frente ao seu instrumento e não tocou absolutamente 
nenhuma nota por quatro minutos e trinta e três segundos, divididos em três movimentos - intervalos de tempo de 33", 2'40" e 1'20" - marcados por um cronômetro posto sobre o piano e pontuados pelo abrir e fechar do tampo do teclado. Essa peça, que entra para o hall das chamadas theatre pieces de Cage, remete a uma situação musico-teatral ${ }^{3}$ que vem a explicitar que o silêncio-ausência é um mito construído por uma sociedade antropocêntrica. Com ela, Cage transporta o silêncio para o patamar artístico de forma ativa, ao mesmo tempo que desconstrói o dualismo e as barreiras existentes entre som/ruído e silêncio (FORGET, 1995, p. 2). Logo, a única distinção que deveria existir no âmbito sonoro se daria entre o que produzimos de forma intencional ou não. Ademais, durante o concerto, a plateia toma lugar na execução da obra visto que inevitavelmente produz sons ao acaso que serão evidenciados na situação artística silenciosa. Não mais restrita aos limites do palco ou da orquestra, a obra musical se junta e se confunde com a paisagem sonora, se construindo para além de um objeto que deve ficar fechado dentro de uma bolha de silêncio. Ela se mistura e é complementada pelos sons ambientes, pelos sons do público, enfim, por toda a situação que é mise en place. Nesse sentido, a obra se apresenta não mais como o resultado de um processo criativo, e sim como o próprio processo (VILLA, 2013, p. 402).

A segunda peça silenciosa de Cage, datada de 1962, traz à tona mais reflexões sobre o silêncio. Na teoria, a única qualidade acústica atribuída ao silêncio seria a sua duração, em contraste com o som que tem como propriedade altura, intensidade, duração e timbre. Em o'oo”, a organização temporal desaparece por completo, e nela, o tempo é a duração pura do instante no qual qualquer coisa ou ritmo podem se produzir (SALGADO, 2007, p. 52). Segundo o próprio autor, trata-se de um ato performático de uma ação qualquer a ser realizada com máxima amplificação sonora. A primeira performance de $O$ 'oo" foi realizada durante o escrever do próprio manuscrito que continha as indicações da obra. Em 5 de maio de 1965, essa performance foi apresentada no Rose Art Museum, em Massachusetts. O compositor Alvin Lucien, presente durante a performance, descreve o acontecimento da seguinte forma:

Cage começou a performatizar o'oo" antes que a audiência entrasse. Ele estava sentado em sua cadeira cheia de rangidos e amplificada, com um microfone de piloto de aeronáutica da Segunda Guerra Mundial enrolado em volta da sua garganta, escrevendo cartas numa máquina de escrever amplificada, e ocasionalmente bebendo goles d'água. Parte da intenção da peça é fazer 
algum trabalho que você faria de qualquer forma, e John escolheu responder algumas correspondências. Cada movimento que ele fazia, cada rangido de sua cadeira, toque em sua máquina de escrever e gole d'água eram enormemente amplificados e transmitidos através das caixas de som espalhadas pelo museu. (HELLER, 2011, p. 59).

Essas obras nos mostram que a construção do que nós percebemos como silêncio - assim como sons musicais e ruídos - depende da situação na qual estamos inseridos e não de uma objetividade física (que pode, por exemplo, ser medida em escalas e níveis de pressão acústica). Fazer com que sons corriqueiros, para os quais muitas das vezes não damos atenção, destaquem-se e passem ao "primeiro plano auditivo" nos evoca também a relação cultural e coletiva, na qual nos inserimos: enquanto para alguns certos níveis sonoros são cotidianos, para outros são totalmente inaceitáveis. Assim, tanto 4'33" quanto o'oo" operam com os efeitos do silêncio, não ele em si, dada sua impossibilidade de execução. Para Cage, o termo silêncio evoca ainda múltiplas características das quais um estado mental e, sobretudo, uma disposição de espírito. Essa constatação nos propõe a necessidade de um delineamento na polissemia intrínseca do conceito de silêncio. Conforme o exposto e descartando-se a ideia de um silêncio material, acústico, neste trabalho desenvolveremos principalmente reflexões sobre o silêncio enquanto uma dimensão de significação e expressão dentro do cinema. Em outras palavras, a utilização do termo "silêncio" nas situações que serão apresentadas a seguir adquirirem sentidos simbólicos que visam caracterizar as representações que, uma vez projetadas cinematograficamente, estimulam no espectador à sensação de silêncio. Embora não haja silêncio no sentido absoluto por razões supracitadas, desenvolvemos em torno da escuta de algo que é percebido como tal.

\section{A representação audiovisual do silêncio}

Mesmo com a inserção da trilha sonora no cinema, certa estética do silêncio tem seu lugar na produção fílmica contemporânea. Provenientes de um contexto de dominância sonora que afeta tanto a grande indústria como as produções independentes, os chamados "verdadeiros filmes silenciosos" de Camper, ou apenas filmes silenciosos contemporâneos, enfrentam, por isso, uma condição particular em sua existência: a cultura ocidental que se inaugura com a modernidade é saturada por sons e ruídos, de 
forma que parecemos ter perdido as oportunidades ou mesmo a capacidade de experienciar o silêncio que, entretanto, ainda vive entre nós à sua maneira (CAMPER, 1985). É nesse sentido que Susan Sontag afirma que "a arte de nosso tempo é ruidosa, com apelos ao silêncio" (SONTAG, 1987).

A resistência de integrantes do segmento artístico da sociedade à implantação do som nos filmes é notória (WEIS e BELTON, 1985, Parte II). Esses estudiosos alegavam, entre outras coisas, a perda da universalidade dessas obras. Por volta de 1923, o escritor Bela Balazs (1985), afirmava que o cinema tido como "mudo" era capaz de reeducar nossos sentidos e restaurar a capacidade de decifrarmos o mundo visível por meio de uma linguagem sem palavras. Em uma revisão do seu trabalho, já em 1945, ele declara que o potencial do cinema sonoro está na sua habilidade de recuperar certas sensações perdidas, como ouvir sons sutis de objetos, natureza e outros espaços, assim como a escuta do "som do silêncio" (RIBRANDT, 1999, p. 17 e 18). É notório que as opiniões, assim como os modos de escuta, se transformaram em paralelo às mutações tecnológicas que possibilitaram, entre outras, a sincronização do som com a imagem no cinema.

Em análises do cinema que se faz hoje, alguns pesquisadores chamam nossa atenção ao fato de que, segundo o entorno cultural no qual se insere, o cinema contemporâneo pode enfrentar dificuldades em representar o silêncio.

Quando aparece, é breve porque a narrativa tem que se desenvolver rapidamente, sob o olhar de uma audiência pouco habituada a se deixar levar pelo tempo da imagem... e pelo tempo do silêncio. O espectador deixa-se seduzir pela artificialidade da imagem (o efeito visual) ou pelo dinamismo da montagem. Há pouco espaço para o silêncio: é a ovelha negra do cinema de hoje. Sinônimo de tempo morto, de espaço em que nada acontece, de momento particularmente entediante, o silêncio é evitado. E quando é utilizado, tem que ser curto para não aborrecer o espectador. (GIL, 2011, p. 177).

Diante da inviabilidade da execução do silêncio em sua forma plena, o cinema encontra meios diversificados para representá-lo na articulação da linguagem que lhe é própria. Os filmes contemporâneos mobilizam então enquadramentos, movimentos de câmera, luz, direção de arte, atuação, qualidades sonoras e demais elementos a fim de simulá-lo ou talvez estimular nos espectadores a sua apreensão. É importante 
enfatizar que a abrangência de representações possíveis, bem como a capacidade inerente à nossa percepção de interpretar estímulos atribuindo a eles atributos e sentidos variados, faz com que o silêncio possa ser significado e ressignificado conforme o contexto narrativo de sua aplicação. Há ainda um "complexo sistema simbólico que se instituiu ao longo dos anos, estando em jogo longas tradições que sedimentam os modos de interpretação da escuta" (WISNIK, 1999). Logo, para além de um sistema de representações pautado em uma linguagem artística cujos códigos tendem a ser preestabelecidos, é necessário que se compreenda que existe uma relativização dos modos de construção perceptiva do público, engendrando um processo complexo guiado por pressupostos culturais, identidade e repertório geral daqueles que vivenciam essas situações fílmicas "silenciosas".

Diante disto, o silêncio caracteriza-se como um discurso, um elemento da linguagem artística. Nos termos da construção da trilha sonora de um filme, Martin Rubin (1985) declara que existem três principais discursos que fazem parte de sua composição: diálogo, ambiência (background noise) e música, sendo que o silêncio se configuraria como o quarto. A ele é atribuída uma grande riqueza semântica, quando empregado, por não explicitar seu sentido, inaugurando consigo uma série de possibilidades de interpretação, de "imputação de discurso" (SONTAG, 1987). Assim, considera-se que o silêncio e a linguagem se transcendem em um movimento convergente: do mesmo modo que a linguagem aponta para sua própria transcendência no silêncio, em uma aparente suspensão da emissão, o silêncio aponta para sua própria transcendência para um discurso além si, com sentidos e significados mais profundos do que não fora explicitamente proclamado (SONTAG, 1987). Nesses termos, o silêncio remete ao não-dito, evitando em geral a frequente redundância que os diálogos desenvolvem com a imagem e permitindo à imaginação do espectador uma liberdade mais ampla.

\section{Exemplos de composições cinematográficas do silêncio}

Na Trilogia da Incomunicabilidade, de Michelangelo Antonioni, temos um grande exemplo da forma como a dinâmica de imputação de discurso ao silêncio se constrói. Realizada na década de 1960, a Trilogia constitui-se de uma série de três filmes que retratam as dificuldades que as pessoas têm de se conectarem umas com as outras, de expressarem seus sentimentos. São eles A Aventura (L'Avventura, 1960), A Noite (La Notte, 1961) e O Eclipse (L'Eclisse, 1962). Para realizar essa abordagem, o 
cineasta frequentemente lança mão do silêncio, interrompendo ou mesmo substituindo diálogos inteiros por minutos de olhares profundos e pensamentos não proferidos - sobretudo nos momentos de confronto de $A$ Noite, obra na qual as tensões do enredo não culminam de forma que mostrem alguma resolução para a história. No filme, Giovanni e Lidia, que conduzem um casamento desgastado há anos, vão a uma grande festa e lá ambos buscam distração entre os convidados. Ele se interessa subitamente por Valentina, com quem vive um affair naquela noite. Cientes do ocorrido, ao se despedirem no fim da festa, em vez de deixarem todos os sentimentos latentes naquela situação constrangedora virem à tona, o casal e a amante se reservaram a formalidades, seguidas de intensas troca de olhares. Nesses espaços abertos pelo silêncio, cabe ao espectador desvendar o significado dos gestos e expressões dos personagens, e construí-los de forma que contribua no encadeamento causal da narrativa proposta. Em A Aventura, as “ausências” são oferecidas como espaços de experiência.

Sob os diversos aspectos que se coadunam para materializar o silêncio na obra de Antonioni, é notória a ausência de voz humana na trilha como uma qualidade silenciosa, o que revela referido caráter antropocêntrico da construção ocidental do silêncio. Isso reafirma a alegação de Michel Chion acerca da centralidade vocal - e mais precisamente verbal - na qual se pauta a constituição do áudio cinematográfico (CHION, 2005, p. 9).

Além do caso citado, tem-se como referência o início de $O$ Eclipse (1962), no qual nos deparamos com mais de dois minutos e meio de silêncio por parte de Riccardo e Vittoria, que aparentemente acabaram de ter uma grande discussão e se encontram no fim do seu relacionamento. Depois da troca de poucas frases, mais uma vez o silêncio das palavras não ditas e uma intensa troca de olhares tomam lugar na cena. Para se ressaltar a ausência da voz humana, o desenho de som é composto principalmente pela forte presença do ruído de um ventilador, e também por pontuais intervenções do toque dos objetos sobre os móveis, do barulho de passos e do afastar de cortinas.

Vemos que aos sons sutis, para os quais geralmente não dedicamos tanta atenção, é atribuída maior intensidade e nitidez, e assim é estabelecida pelo filme uma sensação de silêncio. Paradoxalmente, essa sensação é recriada com a materialização de sons específicos, incrementados por vezes com certa reverberação - um aspecto sonoro próprio aos ambientes internos que nos permite perceber o volume dos lugares e a distância das fontes sonoras, mas também os grandes espaços vazios. Vemos ainda em outros exemplos a utilização do cricrilar dos grilos, latido de cães, assobio do vento, 
Figura 1

Os olhares intensos entre os personagens no momento de confronto do filme $A$ Noite

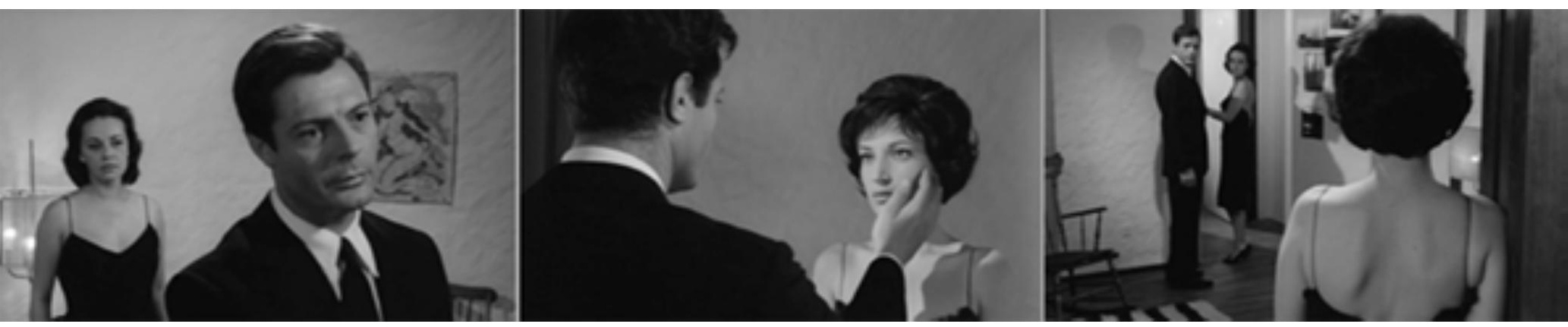

Figura 2

O silêncio marcado por minutos de ausência de voz humana em $O$ Eclipse
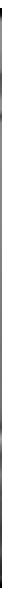

respiração, folhas balançando e "tic-tac" de relógios. A composição do silêncio se dá por meio de qualidades silenciosas, articuladas junto ao contexto narrativo (TEREZANI, 2013). Bela Balazs descreve essas qualidades mostrando como a percepção do silêncio ocorre por meio delas:

Como percebemos silêncio? Escutando nada? Essa é uma mera negativa. No entanto o homem tem poucas experiências mais positivas do que a experiência do silêncio. Pessoas surdas não sabem o que ele é. Mas se a brisa da manhã sopra o som de um galo cantando para nós do vilarejo vizinho, se do topo de uma alta montanha nós ouvimos a batida de o machado de um lenhador ao longe vale abaixo, se nós podemos ouvir o estalo de um chicote a uma milha de distância - então nós estaremos ouvindo o silêncio ao nosso redor. (BALAZS, 1985, p. 118, tradução nossa). 
Tendo em mente essa descrição, em O Silêncio (1964), Ingmar Bergman manipula elementos sonoros de maneira similar ao trabalho de Antonioni já citado. Por exemplo, o diretor sueco também trabalha o laconismo dos personagens e a inserção de sons cotidianos pontuais e bem definidos na trilha sonora. Para uma estética do silêncio, comumente avalia-se como necessário reconhecer um meio circundante de som e linguagem para admiti-lo, uma vez que ele depende da presença de seu oposto, assim como esquerda/direita, em cima/embaixo (SONTAG, 1987). Determina-se, por meio desse recurso, um referencial do que é considerado como silencioso/ruidoso em dada situação.

A história contada pelo filme de Bergman trata da viagem das irmãs Ester e Anna, cujo relacionamento conturbado e cheio de mágoas se revela aos poucos durante a narrativa. Ester é mais velha, intelectualizada e, encontrando-se doente em estágio terminal, teme a morte. Anna é jovem, vaidosa e, enquanto aspira viver romances, negligencia Johan, o filho que a acompanha. O longa-metragem, junto de Através de um Espelho (Såsom i en Spegel, 1961) e Luz de Inverno (Nattvardsgästerna, 1963), faz parte da Trilogia do Silêncio ou Trilogia da Fé na qual o cineasta parece almejar se referir ao silêncio de Deus mediante as aflições humanas, à falta de intervenção divina (MESQUITA, 2013).

O Silêncio, último filme da série, começa com essas três personagens dentro de um trem. Elas não interagem entre si e não se ouve quase nenhum ruído de início. O silêncio parece, em seu aspecto geral, expressar a frieza entre aquela família, o desconforto, a distância e a solidão. Para auxiliar na transmissão dessa sensação silenciosa que permeia grande parte da obra é utilizado senão o som diegético, mas ainda, o referido uso do contraponto entre planos sonoros e silenciosos. Quando Ester está no hotel e busca se distrair, liga o rádio para ouvir música, ação essa que representa uma quebra de toda composição sonora que antes fora mostrada pelo filme até então. Pouco depois, exacerbando a diferença recém-estabelecida, Ester vai até a janela. A câmera, que a filma do lado de fora, firma um ponto de escuta a partir da rua que revela uma paisagem sonora barulhenta, com o som de buzinas e tráfego de automóveis. Dessa forma, identifica-se um cenário circundante de sons dentro do qual se situa o silêncio - e seus valores simbólicos - vivido por Johan, Anna e Ester. A articulação na forma de contraponto entre momentos silenciosos e ruidosos pode acentuar ao mesmo tempo a sensação silenciosa de uma cena como colocar em valor os sons de uma outra, anterior ou subsequente. Michel Chion (2011) considera essa alternância 
como a principal possibilidade de se empregar a impressão silenciosa - estabelecida por meio de sons - na linguagem cinematográfica. Vemos que o silêncio atravessa inúmeras formas de representação, não sendo, portanto, suficiente sua mera exclusão da trilha sonora. A sensação de ruptura e de contraste sonoro seria assim fundamental para que o silêncio cinematográfico seja percebido.

Figura 3

A construção visual do silêncio na obra O Silêncio, de Bergman, reforçando o vazio e o abandono
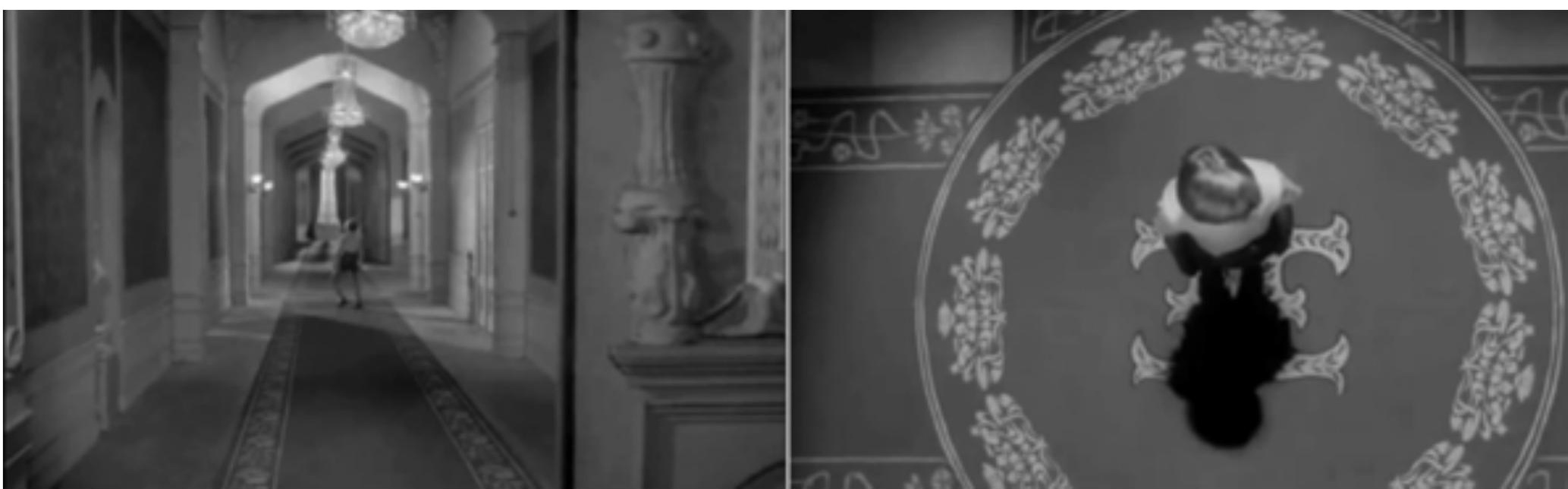

Ainda na obra de Bergman, podemos citar o frequente tédio expressado por Johan como um marcador desse silêncio simbólico, uma reação explícita do personagem à atmosfera incômoda e morosa que o cerca. Como uma criança, ele procura suprir o "vazio" com suas brincadeiras, produzindo diversos sons para ocupar o espaço deixado pela ausência de ruído em seu entorno que, por vezes, também pode ser uma representação da ausência de atenção a ele dedicada. Em termos visuais, temos uma composição com grande área de respiro na imagem, quadro aberto e um ambiente que se mostra vazio quando Johan passeia sozinho pelos corredores do hotel. A sensação de solidão e quietude é reforçada pela maneira como os elementos encontram-se organizados no enquadramento.

Dessa forma, é possível notar que a linguagem visual aplicada à representação do silêncio pode alcançar diferentes níveis de complexidade. Para explorar os meandros dessa complexidade, passemos à obra Luz Silenciosa (Stellet Licht, 2007), de Carlos Reygadas. No intuito de transmitir a morosidade com a qual a vida das personagens se 


\section{Figura 4}

A articulação dos elementos luz e som em Luz Silenciosa. Na medida em que se estabelece uma profusão de luz em quadro, a intensidade sonora diminui, e vice-versa.

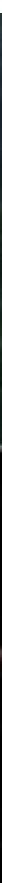

passa, a quietude do ambiente rural e a frieza que permeia algumas ações retratadas, o cineasta opta pela construção de uma impressão silenciosa no decorrer de todo o filme. Os planos estáticos, a câmera de movimentos vagarosos e fluidos, a utilização de planos-sequência e a edição com poucos cortes se juntam para dar corpo a essa estética.

A trama é protagonizada por Johan, fazendeiro de uma comunidade menonita que se caracteriza pela fidelidade aos preceitos cristãos e rejeição aos progressos tecnológicos e culturais da sociedade contemporânea. Contrariando sua religião, mantém um caso com uma mulher fora de seu casamento e, com isso, vive uma crise. Sente-se mal ao encarar sua esposa e é questionado pelas pessoas com quem convive. Ao contrário do que se possa supor por essa breve exposição, a trama não tem um tom passional e, aparentemente, não envolve emoções arrebatadoras. A angústia e a culpa internalizadas de Johan se expressam por meio do silêncio e a narrativa é conduzida de maneira lenta e pesada. No começo do filme presenciamos sua angústia após ter sido deixado sozinho em casa por sua família que vai ao culto. O silêncio é tamanho 
que o forte "tic-tac" do relógio o incomoda e ele o desliga, o que também pode representar uma tentativa de "parar o tempo" mediante sua agonia. Johan vive então uma profunda reflexão em um único plano, estático na maior parte do tempo, que sofre a alteração de uma pequena aproximação da câmera em direção à personagem, somente. O plano silencioso dura três minutos e vinte segundos, tempo que, para as características dominantes de uma linguagem cinematográfica comercial, convencionada, indica a assinatura de um estilo diferenciado.

Outro exemplo da articulação dessa linguagem que faz conjunto com a configuração de uma impressão silenciosa é quando ele vai ao encontro de sua amante. A câmera segue seus pés em um plano-sequência. Ouve-se o som das plantas sendo amassadas pelas pisadas de sua bota até que eles estejam frente a frente. Em outro plano, os dois se encaram de perfil para a câmera. Eles se beijam e se abraçam por quase dois minutos, somente ao som do vento. A partir disso, é interessante notar a forma como essa obra não articula um encadeamento convencional das ações. Considera-se que no cinema clássico, quando uma ação já foi devidamente estabelecida na narrativa e mostrada por tempo suficiente (que, em geral, é pouco) para que seja apreendida pelo espectador, pode-se partir para a ação seguinte. No filme inteiro existe esse "excesso" de tempo em muitos planos. Também, por diversas vezes, mostra-se durante a história o que pode ser considerado como "tempo morto" em quadro, ou seja, instantes em que os personagens não estão desempenhando nenhuma ação que possa ser considerada como relevante para o desencadeamento dos fatos.

É interessante observar que, dentro de uma narrativa específica, pode-se estabelecer a oposição de aspectos visuais para que em seus devidos contextos, representem som ou silêncio. Em Luz Silenciosa, a composição fotográfica de um quadro com mais ou menos luz indica, respectivamente, menos e mais som. Essa relação dicotômica é geralmente articulada dentro dos planos de longa duração. Isso ocorre, por exemplo, na citada cena do beijo que é acompanhada somente pelo som vento e uma forte luz que invade o quadro; em oposição à cena em que a esposa de Johan, Esther, morre no meio de uma tempestade, entre as árvores, submersa em uma atmosfera sombria. Igualmente, o instante da ressurreição de Esther, carregado de uma sensação silenciosa, contrasta-se com a viagem de carro da família que se dá na escuridão da noite e é acompanhada pelo forte som das cigarras (REIS, 2013, p. 100-101). 
Figura 5

A composição de cena em Solaris com qualidades silenciosas visuais: cores frias, grande área de respiro no enquadramento e plasticidade do ambiente natural

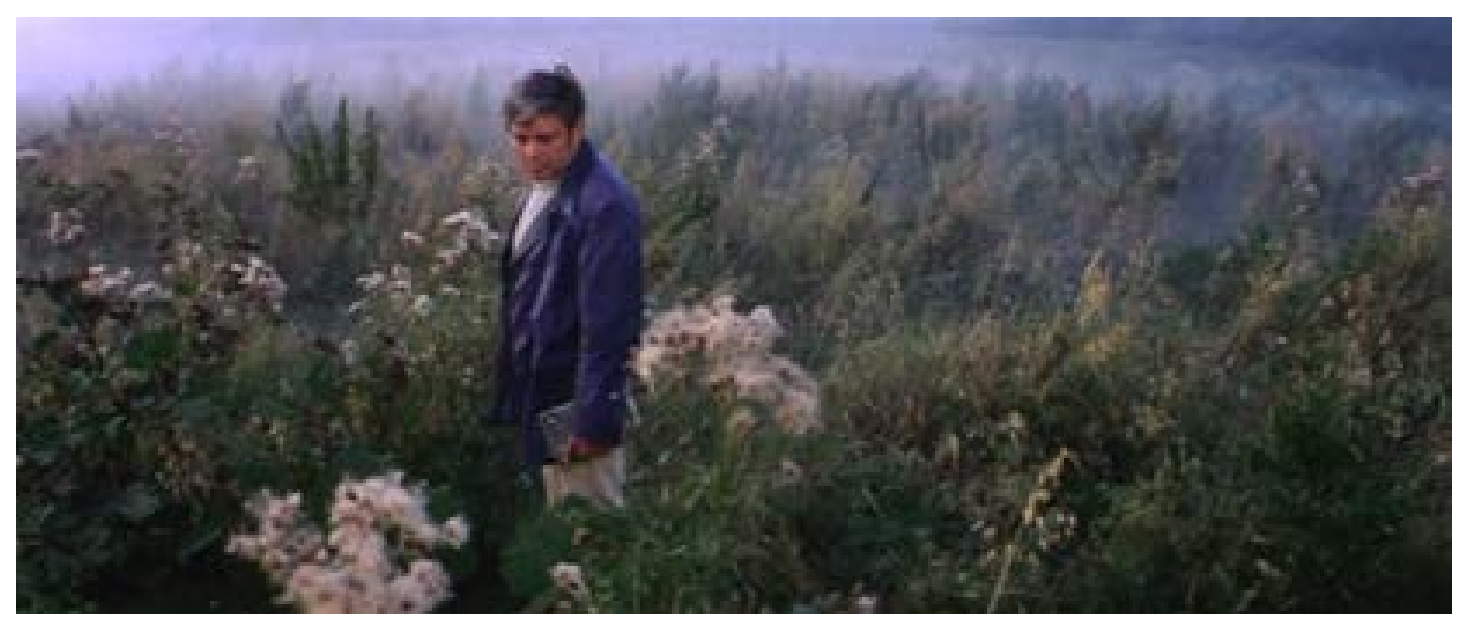

Com isso, nota-se que o silêncio também é comumente agregado a contextos narrativos que fogem do cenário urbano, tal qual a obra citada de Reygadas, em que a trama se passa em uma comunidade rural, mas também em outras, como Solaris (Solyaris, 1973) de Andrei Tarkovsky e 2001: Uma Odisseia no Espaço (2001: A Space Odyssey, 1968), de Stanley Kubrick. Todavia, cada um dos filmes apresenta uma abordagem própria.

Primeiramente, em Solaris é possível verificarmos um outro tipo de construção visual do silêncio na primeira sequência do filme. Solitário e melancólico por motivos ainda desconhecidos pelo espectador, o protagonista, doutor Kris Kelvin, vaga por entre os arbustos e pedras. Na cena, a sensação silenciosa é construída pelo som da água correndo pelo rio e o cantar dos pássaros como qualidades sonoras acústicas, enquanto visualmente a cena é construída pela plasticidade da natureza. Aí se relaciona a ausência da intervenção humana no ambiente natural com a suspensão de ruído, assim como pelas cores frias.

No filme, o doutor Kris Kelvin, renomado psiquiatra, é enviado à estação espacial que orbita o planeta Solaris para investigar os estranhos acontecimentos que têm abatido a tripulação que fora enviada para uma missão de descobrimento de vida extraterrestre. Nessa trama, os fatos são permeados por grande mistério. O oceano do planeta incita alucinações nos cientistas e pesquisadores, e o silêncio é utilizado como ferramenta de promoção de suspense para expressar o desconhecido, a perturbação diante do incompreensível. 
Figura 6

A exclusão total da trilha sonora se junta ao espaço vazio no enquadramento para transmitir

a sensação silenciosa em 2001

Por sua vez, com temática similar à de Solaris, o filme 2001: Uma Odisseia no Espaço (1968) carrega consigo o silêncio com a mesma intenção, entretanto opta por uma construção diferente. Nele, a trilha sonora é completamente eliminada da linha de edição. No enredo, quando o sistema de inteligência artificial que controla a missão, HAL 9000, começa a revelar sua verdadeira natureza controladora, suspende o oxigênio e a ligação do astronauta Frank com a nave enquanto ele estava consertando o equipamento de comunicação danificado que se localizava do lado de fora da estrutura, no espaço. Mostrando os últimos instantes de vida e aflição dele, desesperado e rodopiando, o diretor, ao retratar o espaço, opta pela ausência completa de trilha na narrativa em vista de representar a ausência de som no vácuo, o que acaba por reforçar o suspense e a dramaticidade do momento. A fotografia também dá sua contribuição ao deixar em quadro um grande vazio que mostra imensidão do universo.

Já em oposição ao que Kubrick realizou, em O Poderoso Chefão III (Godfather - Part III, 1991), Francis Ford Coppola explora uma outra maneira de se estabelecer o silêncio na narrativa fílmica. O diretor constrói uma impressão silenciosa que se refere à eliminação dos sons que dizem respeito à dimensão ficcional da obra e às ações da narrativa em cena. Durante a saída do espetáculo, no momento em que a filha de Michael Corleone é assassinada nas escadarias do teatro, ouvem-se tiros e forma-se uma grande confusão. Michael toca em seu próprio peito à procura de ferimentos, afinal, ele é o Don Corleone, mas, para sua amargura, depara-se com sua filha ensanguentada - vítima do legado mafioso que sustentara. Incrédulo, tenta negar a si mesmo o ocorrido e, caindo em si, grita dilacerado pela dor da perda. Nesse instante, 
a música extra-diegética fica mais forte e o som diegético é completamente suspenso. Apesar disso, seu grito pode ser audível mentalmente e seu sofrimento transpassado por meio de uma projeção multissensorial. No fim da cena, o som diegético retorna e ouvimos o seu segundo grito. As eleições estéticas do diretor, nesse exemplo, podem ser interpretadas no sentido de querer dar determinada intensidade à cena junto à representação de um momento solene de luto e perda.

Finalmente, os exemplos elencados e analisados visam demonstrar um pequeno panorama de como a cinematografia contemporânea se relaciona com a representação do silêncio. Evidentemente não há a intenção de se alcançar a totalidade das possibilidades de construção do silêncio que a linguagem do cinema oferece, posto que essa intenção findaria numa tarefa pretensiosa e impossível de ser realizada em vista da criatividade inerente ao meio artístico. O real objetivo da pesquisa é trazer para discussão como a contemporaneidade estabelece uma sensação silenciosa no cinema manipulando recursos sonoros e visuais, propiciando uma experiência sinestésica para o espectador.

Como último filme a ser destacado, mencionamos uma obra brasileira que nos serve para revelar a natureza situacional da percepção do silêncio. Em O Som ao Redor (2012), de Kleber Mendonça Filho, é possível considerar que há uma inversão na utilização dos recursos aqui colocados como integrantes da estética do silêncio. Por meio de uma linguagem que trabalha os ruídos sutis do nosso entorno de forma intensa, em vez de buscar representar o silêncio em sua apreensão de suspensão de sons, o realizador expressa o quanto somos permanentemente rodeados por informações acústicas. Dessa maneira, elabora uma metáfora que aborda a constante tensão que nos cerca, provocada pela falta de segurança da cidade. O som constante representa, no filme, a quebra da tranquilidade. No sentido desenvolvido por Cage, essa construção opõe-se à ideia de silêncio absoluto visto que somos constantemente rodeados por um silêncio composto por ruídos. Nesse filme, nós podemos perceber a sonoridade constante que invade os ambientes.

\section{Considerações finais}

A diversidade de artifícios utilizados na construção do silêncio no cinema tem uma evidente implicação nos significados e valores imanentes ao enredo apresentado. Em termos da construção cultural ocidental da noção de silêncio, vimos que existe um sentido negativo que o termo silêncio, como qualidade sonora, carrega em si. Nos filmes, esse sentido implica em modos de expressão que estão vinculados a representações 
como a imobilidade, o abandono, a ausência, a solidão, o vazio existencial, a tristeza, a melancolia, a morte, entre outros. Ou seja, em uma primeira estância, o silêncio - como recurso narrativo do cinema - opera de maneira similar à concepção do atributo silencioso estabelecido pela sociedade ocidental.

As nuances do silêncio como recurso narrativo são inúmeras, da mesma maneira que as sensações que ele pode incitar junto aos espectadores. Assim, no cinema contemporâneo, a problematização da noção de silêncio como linguagem abarca domínios mais delicados, uma vez que abre mão da possibilidade de expressão sonora explícita para se alcançar determinados efeitos em um público. A sensação silenciosa que emana da tela aporta ao filme uma aura de mistério. Jean Yves Bosseur (1993) sublinha que, sendo um discurso, o silêncio se configura como um convite ao público para decifrá-lo. Público que, na sua vida cotidiana, não está habituado à sensação de ausência que o silêncio cinematográfico provoca. Quando aplicado na obra artística, ele visa estabelecer a sensação silenciosa como um elemento diferencial. Vê-se que o silêncio, apropriado pelo cinema e representado pela articulação audiovisual, proporciona um espaço de abertura. Um espaço dentro do qual o espectador pode se inserir. Cage (1961) já intencionava pôr esse tipo de experiência estética em seus trabalhos e fez os sons do público tomarem parte na execução constituindo o material sonoro de sua peça. De maneira análoga, a sensação silenciosa pode ser construída não somente pelo cineasta que mobiliza a linguagem em torno de suas propostas, como também pela plateia, em uma experiência estética que pode conter uma parcela de estranhamento da parte do público. Um fator desconcertante que seria exatamente o que o impele a participar da obra. O público é assim convidado a olhar para a imagem filmica com uma nova perspectiva, um novo ponto de escuta. Os sentidos se põem a trabalhar a fim de "completar" esse espaço vazio disponibilizado. Espaço no qual o espectador pode se colocar a fim de construir uma nova experiência, no sentido de uma interação mais ativa com a obra que, nesses momentos, adquire características de uma obra aberta, incitando ainda mais o imaginário do espectador.

Se, imerso em certo viés cultural, o silêncio reflete a inatividade, na obra de arte ele parece solicitar ativamente a participação. Ao que nossa consciência responde performando intuitivamente conforme a situação. A partir da análise da experiência estética pautada na fruição do silêncio, podemos constatar justamente o contrário da inatividade ou da ausência culturalmente a ele atribuída. O cineasta oferece assim deliberadamente uma obra para se construir perceptivamente de forma ativa, imaginativa, estimulando o espectador nessa experiência. 


\section{Notas}

1. Em seu manifesto A Arte dos Ruídos, de 1914, Russolo afirma que "a vida antiga foi toda silêncio. No século dezenove, com a invenção das máquinas, nasce o ruído" (RUSSOLO, 1916, p. 9, tradução nossa).

2. O conceito de "paisagem sonora" (soundscape) que, em linhas gerais, define hoje esse tipo de pensamento, só seria proposto bem mais tarde nos anos 1970 pelo pesquisador e compositor canadense Murray Schafer e adquire grande divulgação em 1977 com sua obra The Tuning of the World (SCHAFER, 2011).

3. Sobre essa peça, Cage interpela: "What could be more theatrical than the silent piece? Somebody comes on stage and does absolutely nothing” (FETTERMAN, 1996, p. 84).

\section{Referências}

ATTALI, Jacques. Bruit. 35. ed. Vendôme: Presses Universitaires de France, 1977.

BALAZS, Bela. Theory of the film: Sound. In: WEIS E.; BELTON, J. Film Sound: theory and practice. New York: Columbia University Press, 1985.

BOSSEUR, Jean Yves. John Cage. Paris: Minerve, 1993.

CAGE, John. Silence. 1. ed. Connecticut: Wesleyan University Press, 1961.

CAGE, John.A Year from Monday: New Lectures and Writings by John Cage. Wesleyan University Press, Hanover, 1967.

CAMPER, Fred. Sound and Silence in Narrative and Nonnarrative Cinema. In: WEIS, E.; BELTON, J. Film Sound: Theory and Practice. New York: Columbia University Press, 1985.

CHION, Michel. L'Audio-vision. 2. ed. Paris: Éditions Armand Colin, 2005.

FETTERMAN, William. John Cages's Theatre Pieces: Notations and Performances, Amsterdam: Harwood Academic Publishers, 1996. 
FORGET, M. C. Du mutique à l'objectal: la notion de silence chez John Cage. In:FORGET, M. C. Musique et silence. Paris: CIREM, 1995.

FRANCON DE COLOGNE. Ars Cantus Mensurabilis (XIII século). Texto original integral editado por NAVARRE, Jean-Philippe. Paris: Ed. du Cerf, 1997.

GIL, Inês. O som do silêncio no cinema e na fotografia. Babilônia, Lisboa, número especial, p. 177-185, 2011.

HELLER, Alberto Andrés. John Cage e a poética do silêncio. Blumenau: Letras Contemporâneas, 2011.

MANZANO, Luiz. Som-imagem no cinema. São Paulo: Perspectiva, 2010.

MENDONÇA, Gilberto Teles. Vanguarda européia e modernismo brasileiro: apresentação e crítica dos principais manifestos vanguardistas. 20. ed. Rio de Janeiro: José Olympo Editora, 2012.

MESQUITA, Raphael. Trilogia do silêncio. Contracampo. São Paulo, n. 79, 2013.

POPPER, Frank. Art - action et participation 1 - le déclin de l'objet. Paris; Chêne, 1975.

POPPER, Frank. Art - action et participation 2 - l'artiste et la créativité aujourd'hui. Paris: Klincksieck, 1980.

REIS, Hugo. Sobre a Luz e o Silêncio: o plano de longa duração e a dinâmica do som no cinema de Carlos Reygadas.2013. Dissertação (Mestrado em Imagem e Som) - Universidade Federal de São Carlos, São Carlos, 2013.

RIBRANDT, Gunnar. Style Parameters in Film Sound. Uppsats Framlagd Vid Seminariet. Estocolmo, n. 30, v. 1, 1999. Disponível em: http://filmsound.org/bibliography/stylepara.pdf. Acesso em: 8 ago. 2016.

RUBIN, Martin. The Voice of Silence: Sound Style in John Stahl's Backstreet. In: WEIS, 
E.; BELTON, J. Film Sound: Theory and Practice. New York: Columbia University Press, 1985 .

RUSSOLO, Luigi. L'arte dei rumori. Milano: Edizioni Futuriste di “Poesia”, 1916.

SALGADO, Carmen Pardo. Approche de John Cage: l'écoute oblique. Paris: L'Harma$\operatorname{ttan}, 2007$.

SCHAFER, Murray R. A afinação do mundo. 2. ed. São Paulo: Editora Unesp, 2011.

SONTAG, Susan. A estética do silêncio. In: A vontade radical. São Paulo: Editora Schwarcz, 1987.

TEREZANI, João H. T. Ouvindo vazios: reflexões sobre o silêncio no cinema. In: Seminário Nacional Cinema em Perspectiva, 2., Curitiba, Anais [...]. n. 1, v.1, 2013.

VILLA, André. Reflexions interdisciplinaires sur la perception et la cognition musicales. 2013. Tese (Doutorado em Estética, Ciência e Tecnologia da Arte) - Universite Paris 8, Vincennes, 2013.

WEIS, Elisabeth; BELTON, John. Film Sound: Theory and Practice. New York: Columbia University Press, 1985 .

WISNIK, José Miguel. O som e o sentido. 2. ed. São Paulo: Companhia das Letras, 1999.

\section{Obras}

2001: UMA ODISSÉIA no espaço. Direção: Stanley Kubrick. Produção: Stanley Kubrick. Estados Unidos: Metro-Goldwyn-Mayer,1968.161 min., colorido.

A AVENTURA. Direção: Michelangelo Antonioni. Itália: 1960. 143 min., P\&B.

A NOITE. Direção: Michelangelo Antonioni, Produção: Emanuele Cassuto. Itália: 1961. 122 min., $\mathrm{P} \& \mathrm{~B}$. 
CAGE, John. o'oo" (4'33" n ${ }^{\circ}$ 2), solo para ser executado de qualquer maneira por qualquer pessoa. New York: Edition Peters, 1962.

CAGE, John. 4'33”, para qualquer instrumento ou formação instrumental. New York: Edition Peters, 1952.

LUZ Silenciosa. Direção: Carlos Reygadas, Produção: Jamie Romandia e Carlos Reygadas.México/França: Motel Films, 2007. 136 min., colorido.

O ECLIPSE. Direção: Michelangelo Antonioni. Itália: 1962. 125 min., colorido.

O PODEROSO Chefão: parte III. Direção: Francis Ford Coppola, Produção: Francis Ford Coppola. Estados Unidos: Paramount Pictures, 1990. 170 min., colorido.

O SILÊNCIO, Direção: Ingmar Bergman, Produção: Allan Ekelund, Suécia: 1964. 96 min., $P \& B$.

O SOM ao Redor. Direção: Kleber Mendonça, Produção: Emilie Lesclaux. Brasil: CinemaScópio, 2013. 131 min., colorido.

SOLARIS. Direção: Andrei Tarkovsky, Produção: Viacheslav Tarasov. Rússia: 1973. 169 min., colorido.

VARÈSE, Edgard. Déserts, para instrumentos de sopro, percussões e fita magnética. Milão: Ricordi, 1950-1954.

Recebido em: 16/11/2017

Aceito em: 18/11/2019

Publicado em: 11/03/2020 